\title{
Randomised controlled trial of anti-smoking advice in pregnancy
}

\author{
J. W. DONOVAN*
}

From the Department of Medical Statistics and Epidemiology, London School of Hygiene and Tropical Medicine

SUMMARY In a randomised controlled trial intensive individual anti-smoking advice given in parallel with hospital antenatal care did not influence the outcome of pregnancy. The belief that retardation of fetal growth caused by maternal smoking occurs in late pregnancy is not well based, and the advice may not have been given in time to be effective. Other possible interpretations of the results, that maternal smoking is merely an index of some other factor that retards growth or that those counselled did not reduce their smoking sufficiently to influence outcome, cannot be excluded.

The association between maternal smoking and retarded fetal growth was first described in 1957, and is now well known. Since then, the retardation of growth and development has been shown to persist at least until the age of 11 years, and associations of maternal smoking with increased risks of abortion, perinatal death, and certain malformations have also been described (Butler and Goldstein, 1973; US Public Health Service, 1973). Many of these reports did not consider that the associations might not be cause and effect, and concluded that pregnant patients should be advised against smoking. Others considered that the retarded growth and other effects were caused by smoking, but recognised that proof could be provided only by experiment. The remaining reports claimed that the observed associations were due to some unidentified factor or factors of which smoking was merely an index.

This paper reports on a randomised controlled trial measuring the effects of intensive individual anti-smoking advice given in parallel with hospital antenatal care in a test and a control group. The results of the outcome in these groups are compared with those in three other groups of mothers who had stopped smoking, had never smoked, or who were irregular smokers.

\section{Methods}

Consecutive series of patients who were in contact with three maternity units concerning their hospital confinement were sent by post a reply-paid

* Present address: Department of Health, PO Box 100, Woden, A.C.T. 2606, Australia. questionnaire with the hospital administrative documents. The questionnaire sought information on smoking habits as well as obstetric and medica data. Questionnaires returned at or before the firse antenatal examination were used to select patients for study. Incomplete questionnaires were accepted if patients could be allotted unambiguously to one of the groups described below.

CONTROLLED TRIAL GROUPS

Patients, either married or single, were admitted to the controlled trial if they were currently smoking five or more cigarettes a day and had been smoking one or more cigarettes a day at the beginning of pregnancy, were less than 30 weeks' maturity at first examination, had been born in 1937 or later (in effect aged up to 35 years, as the study was carried out in 1972 and 1973), gave no history of a perinatal death, and were not known to have been seeking termination of pregnancy. A table of random numbers was used to allocate each patient into one of two groups:

\section{The control group}

These patients received the antenatal care usually provided by the hospital, including any anti-smoking advice that might have been given routinely.

\section{The test group}

These patients were seen at each antenatal visit by a doctor who gave intensive individual antismoking advice; the methods used are described elsewhere (Donovan et al., 1975). The doctor also took a standard smoking history at the first visit. Their hospital records were labelled with a request 
for hospital staff to reinforce the advice; general practitioners and local authority clinic doctors sharing care were asked to collaborate.

\section{OTHER SMOKERS}

All current smokers ineligible for the controlled trial were admitted to the study.

\section{STOPPED SMOKERS}

Women who had been smokers at any time during the preceding year but who were not smoking at the time they completed the questionnaire were admitted. All but two of these patients had smoked at the start of the pregnancy.

\section{NON-SMOKERS}

From the women who had not smoked regularly in the previous year but who met the other conditions for the controlled trial a sample was chosen to match the control group for year of birth (within three years), parity $(0,1,2,3+)$, and country of birth (also broadly grouped). Not all control group patients could be matched in this way, and substitutes with incomplete matching were not sought. As a result this group was smaller than those in the controlled trial, particularly for mothers aged 18 and under.

For all groups weights of infants and other measurements made in labour wards were taken from hospital records. As soon as possible after delivery (usually within 48 hours) an interview including a history of smoking was administered in the postnatal ward. The head circumference, crown-rump, and crown-heel lengths of fit babies were measured. Examinations of the baby were repeated about six weeks after confinement.

Patients admitted to the study were excluded if subsequently they were discovered not to be pregnant, refused to participate (consent was sought at the first antenatal visit before smoking was mentioned), had their pregnancies terminated, or ceased attending the hospital before confinement. Nearly all those in the last category are known to have transferred to the care of another hospital, but it is possible that a few miscarried without notifying the hospital and should thus have been retained in the study; as bookings were controlled by the hospital alone and allocation to test or control groups was random this should not have introduced any bias. The numbers in each group, after the exclusions, are shown in Table 1; the term 'miscarried' includes pregnancies ending before 28 weeks measured from the last menstrual period as stated on the questionnaire. In fact, three of these 'premature deliveries' (two test, one non-
Table 1 Numbers in study*

\begin{tabular}{lcccc}
\hline Group & Singleton & Twin & Miscarried & Total \\
\hline Test & 263 & 6 & 11 & 280 \\
Control & 289 & 2 & 17 & 308 \\
Other smokers & 232 & 5 & 8 & 245 \\
Stopped smokers & 175 & -4 & 10 & 185 \\
Non-smokers & 243 & 4 & 9 & 256 \\
Total & 1202 & 17 & 55 & 1274 \\
\hline
\end{tabular}

* For definitions of terms see text.

smoker) survived, although the birthweights of two of them suggested that gross errors had been made in the dates given by the mothers. These pregnancies are not referred to further in this paper; exclusion of the three survivors does not affect the conclusions. The twin pregnancies also are excluded from the analysis. Any discrepancies between the numbers in Table 1 and those in later tables are due to missing items of data.

Social class was derived from statements of occupation using the Classification of Occupations, (Registrar General, 1970). Where occupation was obtained for both parents that of the father was used.

Cigarette consumptions were estimated as follows: in the initial questionnaire patients were asked 'How many cigarettes do you usually smoke per day at present?' and '. . . . a at about the time you became pregnant?' The postnatal interview included the question 'How many cigarettes did you usually smoke each day towards the end of your pregnancy?/ and in the middle months of your pregnancy?/and in early pregnancy?/and before you became pregnant?' Patients who answered with a range (such as 8 to 10) were treated as if smoking at the upper end of the range (in this case 10 cigarettes a day).

Inhaling habits were determined from the interview question: 'When you smoke do you inhale a lot?/inhale a fair amount?/inhale just a little?/ or do you not inhale at all?'

\section{Results}

The results of the descriptive parts of the study were similar to those of earlier studies. For example, mean birthweight in the control group (those who did not receive intensive anti-smoking advice) was $159 \mathrm{~g}$ below that in the non-smoker group, and mean maturity in these two groups was very similar. Characteristics of the groups at entry to the study are given in Table 2 and details of outcome in Table 3.

EFFECT OF COUNSELLING ON PATIENTS The methods of counselling used are described fully elsewhere (Donovan et al., 1975), but some aspects need to be mentioned here. 
Table 2 Comparison of groups at entry into study

\begin{tabular}{|c|c|c|c|c|c|}
\hline & $\begin{array}{l}\text { Test } \\
(263)\end{array}$ & $\begin{array}{l}\text { Control } \\
\text { (289) }\end{array}$ & $\begin{array}{l}\text { Other } \\
\text { smokers } \\
(232)\end{array}$ & $\begin{array}{l}\text { Stopped } \\
\text { smokers } \\
(175)\end{array}$ & $\begin{array}{l}\text { Non- } \\
\text { smokers } \\
(243)\end{array}$ \\
\hline $\begin{array}{l}\text { Cigarettes smoked per day } \\
\text { at entry } \\
\text { at beginning of pregnancy }\end{array}$ & $\begin{array}{l}15 \cdot 2(0 \cdot 4) \\
17 \cdot 9(0 \cdot 4)\end{array}$ & $\begin{array}{l}15 \cdot 2(0.4) \\
17.6(0.4)\end{array}$ & $\begin{array}{l}10 \cdot 3(0 \cdot 6) \\
13 \cdot 2(0 \cdot 7)\end{array}$ & $\stackrel{0}{10 \cdot 8(0.5)}$ & $\begin{array}{l}0 \\
0\end{array}$ \\
\hline Age at last menstrual period & $23 \cdot 8(0 \cdot 3)$ & $24 \cdot 2(0 \cdot 3)$ & $25 \cdot 0(0 \cdot 4)$ & $24 \cdot 8(0 \cdot 4)$ & $24 \cdot 6(0 \cdot 3)$ \\
\hline Maturity at first examination (weeks) & $15.7(0.4)$ & $16 \cdot 2(0 \cdot 3)$ & $18 \cdot 6(0 \cdot 5)$ & $15 \cdot 7(0 \cdot 4)$ & $15 \cdot 2(0 \cdot 3)$ \\
\hline Height (inches) & $63 \cdot 6(0 \cdot 2)$ & $63 \cdot 3(0 \cdot 2)$ & $63 \cdot 9(0 \cdot 2)$ & $63 \cdot 9(0 \cdot 2)$ & $63 \cdot 7(0 \cdot 2)$ \\
\hline $\begin{array}{l}\text { Parity (\%) } \\
\mathbf{0} \\
\mathbf{1} \\
\mathbf{2}+\end{array}$ & $\begin{array}{l}54 \\
33 \\
13\end{array}$ & $\begin{array}{l}54 \\
32 \\
14\end{array}$ & $\begin{array}{l}46 \\
31 \\
23\end{array}$ & $\begin{array}{l}63 \\
27 \\
10\end{array}$ & $\begin{array}{l}58 \\
31 \\
11\end{array}$ \\
\hline $\begin{array}{l}\text { Social class (\%) } \\
\text { I, II } \\
\text { III } \\
\text { IV, V, other }\end{array}$ & $\begin{array}{l}23 \\
50 \\
27\end{array}$ & $\begin{array}{l}23 \\
48 \\
29\end{array}$ & $\begin{array}{l}28 \\
29 \\
33\end{array}$ & $\begin{array}{l}37 \\
38 \\
25\end{array}$ & $\begin{array}{l}39 \\
42 \\
19\end{array}$ \\
\hline $\begin{array}{l}\text { Possess General Certificate of Education or } \\
\text { equivalent }(\%)\end{array}$ & 35 & 35 & 38 & 56 & 64 \\
\hline
\end{tabular}

Mean values, standard errors in parentheses.

Table 3 Comparison of groups at end of study

\begin{tabular}{|c|c|c|c|c|c|}
\hline & $\begin{array}{l}\text { Test } \\
(263)\end{array}$ & $\begin{array}{l}\text { Control } \\
\text { (289) }\end{array}$ & $\begin{array}{l}\text { Other } \\
\text { smokers } \\
(232)\end{array}$ & $\begin{array}{l}\text { Stopped } \\
\text { smokers } \\
(175)\end{array}$ & $\begin{array}{l}\text { Non- } \\
\text { smokers } \\
(243)\end{array}$ \\
\hline $\begin{array}{l}\text { Birth measurements taken at maturity (days) } \\
\text { weight }(\mathrm{g}) \\
\text { below } 250 \mathrm{~g}(\%) \\
\text { before } 36 \text { weeks }(\%) \\
\text { head circumference }(\mathrm{cm}) \\
\text { crown rump length }(\mathrm{cm}) \\
\text { crown heel length }(\mathrm{cm}) \\
\text { placental weight }(\mathrm{g}) \\
\text { passage of meconium (liveborn infant) }(\%)\end{array}$ & $\begin{array}{c}280 \cdot 8(1 \cdot 1) \\
3172 \cdot 0(35 \cdot 0) \\
10 \\
6 \\
34 \cdot 6(0 \cdot 1) \\
33 \cdot 9(0 \cdot 1) \\
49 \cdot 7(0 \cdot 2) \\
646 \cdot 0(9 \cdot 0) \\
16\end{array}$ & $\begin{array}{cc}280 \cdot 4 & (1 \cdot 0) \\
3184 \cdot 0 & (30 \cdot 0) \\
9 & \\
6 & \\
34 \cdot 7 & (0 \cdot 1) \\
33 \cdot 8 & (0 \cdot 2) \\
49 \cdot 8 & (0 \cdot 1) \\
651 \cdot 0 & (8 \cdot 0) \\
17 & \end{array}$ & $\begin{array}{cc}280 \cdot 3 & (1 \cdot 2) \\
3135 \cdot 0 & (34 \cdot 0) \\
8 & \\
6 & \\
34 \cdot 3 & (0 \cdot 1) \\
33 \cdot 4 & (0 \cdot 2) \\
49 \cdot 2 & (0 \cdot 2) \\
616 \cdot 0 & (8 \cdot 0) \\
10 & \end{array}$ & $\begin{array}{l}280 \cdot 8(1 \cdot 3) \\
3347 \cdot 0(41 \cdot 0) \\
5 \\
4 \\
34 \cdot 8(0 \cdot 1) \\
34 \cdot 3(0 \cdot 2) \\
50 \cdot 3(0 \cdot 2) \\
651 \cdot 0(11 \cdot 0) \\
12\end{array}$ & $\begin{array}{cc}280 \cdot 6 & (1 \cdot 0) \\
3341 \cdot 0 & (33 \cdot 0) \\
5 & \\
3 & \\
34 \cdot 9 & (0 \cdot 1) \\
34 \cdot 2 & (0 \cdot 1) \\
50 \cdot 4 & (0 \cdot 2) \\
663 \cdot 0 & (8 \cdot 0) \\
9 & \end{array}$ \\
\hline $\begin{array}{l}\text { Later measurements at age (days) } \\
\text { weight (g) } \\
\text { head circumference (cm) } \\
\text { crown rump length (cm) } \\
\text { crown heel length }(\mathrm{cm})\end{array}$ & $\begin{array}{r}45 \cdot 0(0 \cdot 7) \\
4627 \cdot 0(51 \cdot 0) \\
38 \cdot 2(0 \cdot 1) \\
37 \cdot 9(0 \cdot 2) \\
55 \cdot 7(0 \cdot 2)\end{array}$ & $\begin{array}{r}45 \cdot 7(0 \cdot 7) \\
4658 \cdot 0(50 \cdot 0) \\
38 \cdot 5 \quad(0 \cdot 2) \\
38 \cdot 1 \quad(0 \cdot 2) \\
55 \cdot 8 \quad(0 \cdot 2)\end{array}$ & $\begin{array}{rr}46 \cdot 2 & (0 \cdot 7) \\
4611 \cdot 0 & (52 \cdot 0) \\
38 \cdot 2 & (0 \cdot 1) \\
37 \cdot 8 & (0 \cdot 2) \\
55 \cdot 6 & (0 \cdot 2)\end{array}$ & $\begin{array}{r}45 \cdot 9(0 \cdot 9) \\
4793 \cdot 0(64 \cdot 0) \\
38 \cdot 4 \quad(0 \cdot 1) \\
38 \cdot 5(0 \cdot 2) \\
56 \cdot 4(0 \cdot 3)\end{array}$ & $\begin{array}{r}44 \cdot 6(0 \cdot 5) \\
4692 \cdot 0(47 \cdot 0) \\
38 \cdot 5(0 \cdot 1) \\
38 \cdot 8(0 \cdot 1) \\
56 \cdot 5(0 \cdot 2)\end{array}$ \\
\hline Perinatal deaths & 4 & 1 & 6 & 4 & 3 \\
\hline $\begin{array}{l}\text { Inhaled }(\%) \\
\text { a lot } \\
\text { a fair amount } \\
\text { a little } \\
\text { not at all }\end{array}$ & $\begin{array}{r}23 \\
44 \\
30 \\
3\end{array}$ & $\begin{array}{r}26 \\
39 \\
32 \\
3\end{array}$ & $\begin{array}{l}17 \\
36 \\
37 \\
10\end{array}$ & $\begin{array}{r}16 \\
38 \\
38 \\
9\end{array}$ & E \\
\hline
\end{tabular}

Mean values, standard errors in parentheses; weights of infants and placenta rounded to nearest gram.

In the controlled trial, pregnant patients were to be advised to stop smoking for the sake of the child. As it was not known how they would react to this, efforts were made to anticipate or keep out of the trial patients who might react adversely. For example, for those with a history of perinatal death, anti-smoking advice might have resulted in feelings of guilt. The extent to which patients interpreted counselling as applying to their existing children born of pregnancies in which they smoked, as well as to the current pregnancy, showed that this exclusion was necessary.

Minor objections with which patients attempted to justify continuing smoking were common, but there were four patients in whom counselling had to be abandoned. Two were under psychiatric care, not admitted on the questionnaire, and a third was epileptic, with an aggressive personality. The fourth, so far as could be told, just objected strongly to being advised to do something she did not wish to do; after having a $2350 \mathrm{~g}$ infant she ceased co-operating with the study staff.

General practitioners and local authority doctors sharing in the care of test group patients were requested to reinforce the advice given. The proportions of test and control group patients recalling such advice at postnatal interview were $31 \%$ and $25 \%$ respectively; the difference is not statistically significant.

EFFECT OF COUNSELLING ON OUTCOME At entry to the trial the test and control groups were similar with respect to amounts smoked and to other maternal factors likely to relate to the 
outcome of pregnancy such as age, height, parity, and social and educational status (first two columns of Table 2). At the end of the trial weights, lengths, and head circumferences of the infants at birth and at six weeks were all similar in the two groups. Maturity, placental weight, and incidence of fetal distress and perinatal mortality were also unaffected (first two columns of Table 3).

There was thus no evidence that the anti-smoking advice influenced the outcome of the pregnancies. The rest of this section of the report presents other results of the study that bear on interpretation of this main finding.

\section{RECALL OF AMOUNTS SMOKED}

The postnatal recall of the amounts the subjects believed that they had smoked in early pregnancy can be compared with their contemporaneous statements. At entry to the trial both test and control groups had stated that their mean consumption was $15 \cdot 2$ cigarettes a day (Table 2 ) but at the postnatal interview their estimated consumption, in early pregnancy averaged $17 \cdot 1$ (test) and 14.7 (control) cigarettes a day (Table 4). Responses of each patient at entry and at postnatal interview were therefore compared. In the control group discrepancies in recall were usual, but there was no systematic bias. In the test group postnatal exaggeration of early pregnancy consumption was strongly associated with heavy inhaling (Table 5).

The poor recall of smoking habits is best illustrated by the group of 'stopped smokers', 174 of whom were interviewed postnatally. At this

Table 4 Mean stated amounts smoked at each stage of pregnancy, as obtained at postnatal interview

\begin{tabular}{lll}
\hline Stage of pregnancy & Test & Control \\
\hline Before & $19 \cdot 7(0 \cdot 6)$ & $18 \cdot 3(0 \cdot 5)$ \\
Early & $17 \cdot 1(0 \cdot 6)$ & $14 \cdot 7(0 \cdot 4)$ \\
Mid & $12 \cdot 1(0 \cdot 5)$ & $14 \cdot 7(0 \cdot 6)$ \\
Late & $9 \cdot 2(0 \cdot 6)$ & $16 \cdot 4(0 \cdot 6)$ \\
\hline
\end{tabular}

Standard errors in parentheses.

Table 5 Relationship between inhaling habits and postnatal recall after counselling of amounts smoked in early pregnancy

\begin{tabular}{lll} 
Inhale & & \\
\hline Lot & $\begin{array}{l}\text { Fair } \\
\text { amount }\end{array}$ & $\begin{array}{l}\text { Littlel } \\
\text { not }\end{array}$
\end{tabular}

Patients overestimating consumption in early pregnancy by more than five cigarettes a day Remainder of test group Total

$\begin{array}{rrrr}17 & 19 & 8 & 44 \\ 41 & 98 & 79 & 218 \\ 58 & 117 & 87 & 262\end{array}$

Early pregnancy consumption as recalled postnatally minus current consumption at entry to study versus inhaling. $\chi_{2}^{2}=10 \cdot 12, P<0.01$. interview, 54 admitted smoking in late pregnancy but 11 of them denied ever having stopped. Among the 120 who did not resume, 28 claimed to have given up before they became pregnant (contrasted with two such claims at entry), and three denied ever having been smokers.

\section{REDUCTION IN AMOUNT SMOKED, AND ITS TIMING}

It is a possible interpretation of the results of this controlled trial that the counselling was not acted upon sufficiently, or in time for fetal growth to be affected. As recalled postnatally, the mean stated amount smoked in late pregnancy in the test group was $56 \%(9 \cdot 2 / 16 \cdot 4)$ of that in the control group, and in the middle months it was $82 \%$ of that in the controls (Table 4), and the percentages were similar in each inhaling category. Contemporaneous records of consumption in the test group indicate that the reductions in smoking that were achieved occurred soon after counselling started, with little further reduction after 28 weeks of gestation. However, any interpretation of these findings is made uncertain by the biased recall in the test group.

The number of mothers who change their smoking habits during pregnancy is small if there is no pressure upon them to do so and even with such intervention the proportion who change is not large. As a result statistical analyses which would be able to differentiate between the effects which might be due to smoking at particular stages of pregnancy require large studies. Most earlier studies have only been able to compare mothers who had stopped smoking early in pregnancy with those who did not smoke at all or who continued to smoke. This present study confirms the previous findings that those who stopped smoking had the same outcome as the non-smokers (Table 3) but it also demonstrates that those mothers who reported that they had stopped smoking in early pregnancy had smoked less at the beginning of pregnancy than those who were to continue (Table 2). Many 'stopped smokers' reported that they resumed smoking in late pregnancy which allows a further comparison to be made. Of the 174 'stopped smokers' at the first antenatal attendance, 54 resumed smoking before delivery and their mean consumption at this time was reported as $7 \cdot 0$ cigarettes a day. The birthweight of the infants of these 'resumed smokers' was $3404 \mathrm{~g}$ (standard error $62 \mathrm{~g}$ ) whereas the mean birthweight of the infants delivered by the 120 'persistent stopped smokers' was $3324 \mathrm{~g}$ (standard error $52 \mathrm{~g}$ ). The two groups were similar in other respects including their smoking habits in early pregnancy. The difference of $80 \mathrm{~g}$ between the birthweights is not statistically 
significant but it is in the opposite direction to that which would be expected if smoking in late pregnancy reduced the birth weight of an infant.

OBSERVED GROWTH RETARDATION MAY NOT BE DUE TO SMOKING

The failure of anti-smoking advice to alter outcome is compatible with the hypothesis that smoking in pregnancy does not itself cause low birthweight but that it is an index of some other harmful factor or factors.

One of the arguments used to support this hypothesis concerns the findings of Yerushalmy (1972a) on smokers who were asked the ages at which they had started to smoke. These ages were compared with ages at previous confinements, where birthweights were also known. It was inferred that the patients were or were not smoking during these earlier pregnancies, where the proportions of low (below $2501 \mathrm{~g}$ ) birthweight infants were 8.9\% and $9.5 \%$ respectively. Thus, it was argued, low birthweight was an attribute of the mother and not of whether she smoked in the particular pregnancy.

Those in the test group were asked the age at which smoking was started both at the first antenatal visit and postnatally. There was no systematic error but most patients gave different answers on the two occasions (Table 6). The two sets of answers were

Table 6 Discrepancy between patients' answers to 'How old were you when you began to smoke at least one cigarette per day?' asked at first antenatal visit and again postnatally*

\begin{tabular}{lrr}
\hline Discrepancy (years) & No. & $\%$ \\
\hline None & 125 & $46 \cdot 6$ \\
1 & 95 & $35 \cdot 4$ \\
2 & 28 & $10 \cdot 4$ \\
3 & 9 & $3 \cdot 4$ \\
4 & 5 & $1 \cdot 9$ \\
$5+$ & 6 & $2 \cdot 2$ \\
Total & 268 & $100 \cdot 0$ \\
\hline
\end{tabular}

*Test group only, twin pregnancies included.

therefore checked against dates of previous confinements. If those obtained at the first antenatal visit were correct five patients had their first child before they started smoking. If those obtained at the postnatal interview were correct three patients had their first child before they started smoking. Only one child was in both groups; the other six mothers with pregnancies 'before they started smoking' were unreliable witnesses of the ages at which they had started to smoke. Yerushalmy's interpretation may be based on misclassification due to errors of recall.

One other result which might support the other-factor hypothesis is the lack, within the groups of smokers, of any statistically significant relationship between birthweight and amounts smoked; the major difference was between smokers and non-smokers (details available on request).

\section{Discussion}

The trial did not show any influence of intensive anti-smoking advice on the retardation of fetal growth that descriptive studies have shown to be associated with maternal smoking. It did show that advising patients not to smoke without first determining all relevant circumstances carried risks, and that practising health professionals generally did not reinforce the advice given, even when requested to do so.

From the unanimity of findings of descriptive studies it might have been expected that the antismoking advice would have led to an increase in the mean birthweight of the test group infants. Possible reasons for the apparent conflict are that the counselling may not have been acted upon sufficiently, that any action taken was too late for fetal growth to benefit, or that maternal smoking might be merely an index of some other factor that influences growth. Combinations of these three reasons are also possible.

As no biochemical measurements were made the claimed reductions in smoking cannot be substantiated; the limited evidence that is available may be used to argue both for and against their having occurred. It should, however, be noted that if the findings of Butler et al. (1972) on birthweights associated with changes in smoking habits made around the fourth month of pregnancy are used to calculate expected birthweight in the test and control group infants, the observed outcome is within the limits of chance.

Supporters of the hypothesis that the observed difference in birthweight associated with maternal smoking is due to other factors base most of their arguments on the work of Yerushalmy $(1962,1964$, $1971,1972 a)$. The present study contributes to the dispute over his findings concerning mothers whom he inferred had changed their smoking habits between pregnancies, and strengthens the argument that his analyses were methodologically unsound (Goldstein, 1972; Yerushalmy, 1972b).

One particular finding of the present study that appears to support the other-factors hypothesis is the lack of a gradient of birthweight with amounts smoked. This gradient has been found in larger studies wherever it has been sought. In this smaller study with distortion of stated consumptions in the test group its absence is of no significance. 
TIMING OF ANTI-SMOKING ADVICE

Table 3 shows that the infants of the 'stopped smokers' were similar to those of non-smokers in every respect. From similar findings in many earlier studies it has been inferred that smoking is harmful only in 'later' pregnancy. This inference might be valid if the stopped smokers had in 'early' pregnancy been smoking and inhaling as much as those who continued, but in fact this was not so (Tables 2, 3); only Butler et al. (1972) and Schwartz et al. (1972) seem to have considered this point previously. The experience of smokers who stop smoking early in pregnancy but later resume provides another test of the inference. In the present study, in the group of mothers who resumed smoking in late pregnancy, the mean birthweight was higher than in the group who did not. The only relevant earlier data came from Lowe (1959) who, with similar numbers of subjects, found the reverse. The difference between his findings and those of the present study is compatible with sampling variation.

Where there is a difference in obstetric performance between smokers and non-smokers at a particular stage of pregnancy it can be inferred that smoking if it has an influence is having an influence before that stage. From the larger descriptive studies Yerushalmy (1964) reported higher mean birthweights in non-smokers from before 32 weeks' gestation (Whites) and from 32 weeks (Negroes). Some smaller surveys have found weight differences in pregnancies confined from 28 weeks but others have not (Frazier et al., 1961; Zabriskie, 1963; Russell et al., 1966). Taken together, these surveys indicate that smoking influences outcome of pregnancy at least by 32 weeks, and perhaps by 28 weeks.

There is more direct evidence that smoking is harmful in early pregnancy. There are reports of increased incidence of certain malformations in infants of smokers, although it is generally agreed that the total incidence of malformations is not significantly increased. Likewise several authors have found increased abortion rates in smokers, although others have not (US Public Health Service, 1973).

It is not claimed that this brief review refutes definitively the widely held belief that smoking is harmful to the fetus mainly in late pregnancy, but merely that it is not well based. The current study shows the limited value of smoking histories collected after confinement, and casts doubts on estimates of amounts smoked by those counselled. Further evidence could be provided by large descriptive studies in which smoking habits were recorded throughout pregnancy, with some biochemical testing, and perhaps supported by ultrasonic measurements of fetal growth. Supportive evidence might be provided by animal experiments in which the effect of smoking at each stage of pregnancy was tested; those reported to date have involved exposure throughout pregnancy. The results of controlled trials examining other presumed causes of retarded intrauterine growth might also be relevant. The most direct evidence on the desirable timing of anti-smoking advice would come from controlled trials of advice given before conception and to patients presenting very early in pregnancy, but these would be difficult to execute.

Finally, the late effects on development of retarded intrauterine growth are so important that despite the results of this study it must still be asked what smoking education measures should be used in pregnancy. The answer to this question depends on which of the possible explanations for the difference between the findings of the controlled trial and the inference from previous studies proves to be correct. If the growth retardation can be shown to be caused by some factor other than smoking, anti-smoking advice will be irrelevant. If it is that the advice was acted upon too late, methods that depend upon waiting for patients to get into contact with the health services will also fail. If it is that intensive individual advice was not sufficiently acted upon, other forms of health education may yet prove successful, but their effectiveness should be proved before they are adopted for routine use.

This study was planned during the tenure of a C. J. Martin Travelling Fellowship from the National Health and Medical Research Council of Australia. Its execution was supported by the Tobacco Research Council. The obstetric units of University College Hospital, Hammersmith Hospital, and the Royal Free Hospital collaborated in the study. I wish to thank the study staff for their assistance and Professor D. V. I. Fairweather, Professor J. C. McClure Browne and Professor C. P. Douglas, and the other consultants in their departments, for allowing access to their patients. To Professor D. D. Reid and Mr. G. F. Todd I am grateful for encouragement and advice.

Reprints from the Secretary, Department of Medical Statistics and Epidemiology, London School of Hygiene and Tropical Medicine, Keppel Street, London WC1E 7HT.

\section{References}

Butler, N. R., and Goldstein, H. (1973). Smoking in pregnancy and subsequent child development. British Medical Journal, 4, 573-575. 
Butler, N. R., Goldstein, H., and Ross, E. M. (1972). Cigarette smoking in pregnancy: its influence on birth weight and perinatal mortality. British Medical Journal, 2, 127-130.

Donovan, J. W., Burgess, P. L., Hossack, C. M., and Yudkin, G. D. (1975). Routine advice against smoking in pregnancy. Journal of the Royal College of General Practitioners, 25, 264-268.

Frazier, T. M., Davis, G. H., Goldstein, H., and Goldberg, I. D. (1961). Cigarette smoking and prematurity: a prospective study. American Journal of Obstetrics and Gynecology, 81, 988-998.

Goldstein, H. (1972). Cigarette smoking and lowbirthweight babies. American Journal of Obstetrics and Gynecology, 114, 570-571.

Lowe, C. R. (1959). Effects of mothers' smoking habits on birthweight of their children. British Medical Journal, 2, 673-676.

Registrar General (1970). Classification of Occupations.

Russell, C. S., Taylor, R., and Maddison, R. N. (1966). Some effects of smoking in pregnancy. Journal of Obstetrics and Gynaecology of the British Commonwealth, 73, 742-746.

Schwartz, D., Goujard, J., Kaminski, M., and RumeauRouquette, C. (1972). Smoking and pregnancy. Results of a prospective study of 6989 women. Revue
Europeenne d'etudes cliniques et biologiques, 17, 867-879.

United States Public Health Service (1973). The Health Consequences of Smoking. A Report of the Surgeon General. US Department of Health, Education, and Welfare: Washington.

Yerushalmy, J. (1962). Statistical considerations and evaluation of epidemiological evidence. In Tobacco and Health. Edited by G. James and T. Rosenthal. Thomas: Springfield.

Yerushalmy, J. (1964). Mother's cigarette smoking and survival of infant. American Journal of Obstetrics and Gynecology, 88, 505-518.

Yerushalmy, J. (1971). The relationship of parents' cigarette smoking to outcome of pregnancy-implications as to the problem of inferring causation from observed associations. American Journal of Epidemiology, 93, 443-456.

Yerushalmy, J. (1972a). Infants with low birth weight born before their mothers started to smoke cigarettes. American Journal of Obstetrics and Gynecology, 112, 277-284.

Yerushalmy, J. (1972b). Reply to Mr Goldstein. American Journal of Obstetrics and Gynecology, 114, 571-573.

Zabriskie, J. R. (1963). Effect of cigarette smoking during pregnancy. Study of 2000 cases. Obstetrics and Gynecology, 21, 405-411. 